\title{
Regional Interdependence: A Practical Guidance in Rehabilitation Clinic-Part 2
}

\author{
Luca Collebrusco ${ }^{1,2^{*}}$, Rita Lombardini ${ }^{3}$, Giovanna Censi ${ }^{4}$ \\ ${ }^{1}$ Research Department C.R.O.M.O.N., EDUCAM School, Rome, Italy \\ ${ }^{2}$ Rehabilitation Unit, National Health Service of Umbria, Perugia, Italy \\ ${ }^{3}$ Department of Medicine, University of Perugia, Perugia, Italy \\ ${ }^{4}$ INRCA, University Polytechnic of Marche, Ancona, Italy \\ Email: *tdr.colle@tiscali.it
}

How to cite this paper: Collebrusco, L., Lombardini, R. and Censi, G. (2017) Regional Interdependence: A Practical Guidance in Rehabilitation Clinic-Part 2. Open Journal of Therapy and Rehabilitation, 5, 11-28.

https://doi.org/10.4236/ojtr.2017.51002

Received: November 15, 2016

Accepted: January 2, 2017

Published: January 5, 2017

Copyright $\odot 2017$ by authors and Scientific Research Publishing Inc. This work is licensed under the Creative Commons Attribution International License (CC BY 4.0).

http://creativecommons.org/licenses/by/4.0/

\begin{abstract}
Background: This work has the purpose of describing a well standardized therapeutic path in reference to the article "Regional Interdependence: $A$ model that needs to be integrated in the functional evaluation and Physiotherapy treatment-Part. 1, (doi.org/10.4236/ojtr.2016.43010)" in the form of practical guidance in reference to Figure A1. The approach we describe provides standardized techniques for each joint regional quadrant in order to be used in rehabilitation clinic. Therapeutic techniques will also be classified according to the type of maneuver as classified in the literature.
\end{abstract}

\section{Keywords}

Physical Therapy, Regional Interdependence, Rehabilitation, Visceral Osteopathic, Osteopathic Treatment

\section{Introduction}

The manual treatment consists of a range of direct, indirect, combined, fluid, and reflex-based manual techniques (Figure 1) that are applied to joints, muscles and especially to fascia, a connective tissue that attaches to bones. It permeates the human body, serving mechanical, metabolic and immunological functions. When strained or twisted by overuse or trauma, myofascial structures not only restrict bony mobility, but also compress neurovascular structures and disturb their functions [1]. Indeed, still defined fascia as "the place to look for the cause of disease and the place to consult and begin the action of remedies in all diseases" [2]. The therapist selects a specific manual technique for each segment of each joint regional quadrant according to needs of the patient. The 
techniques will also be classified according to the type of maneuvers described in the literature [3] [4] [5] [6] and will be explained in detail.

\section{Upper Quadrant}

\subsection{HVLA, Dorsal Spine (Upper-Mid Thoracic Segment)}

Supine upper thoracic on mid-thoracic spine thrust manipulation in cervicothoracic flexion. The therapist uses the manipulative hand to stabilize the inferior vertebra of the motion segment targeted and uses the body to push down through the patient's arms, to perform a high-velocity, low-amplitude thrust [5] [7] (Figure 2).

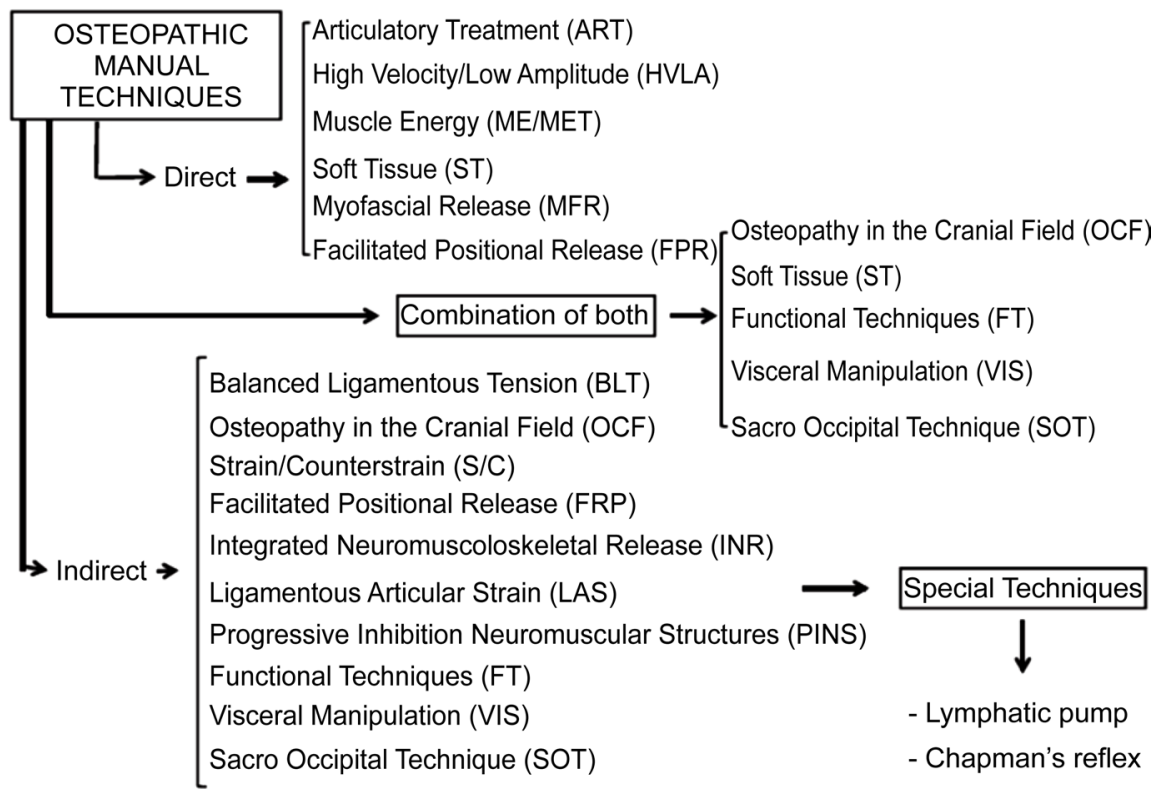

Figure 1. Overview of manual techniques. From: Lombardini R, Collebrusco L. "Osteopathy and Nutrition for managing the Irritable Bowel Syndrome-Brief and useful guide", First Edition, Ed.Universitas Studiorum S.r.l. - Mantova - Italy. ISBN 9788899459321, pag. 75, DOI: 10.13140/RG.2.1.1633.4965.

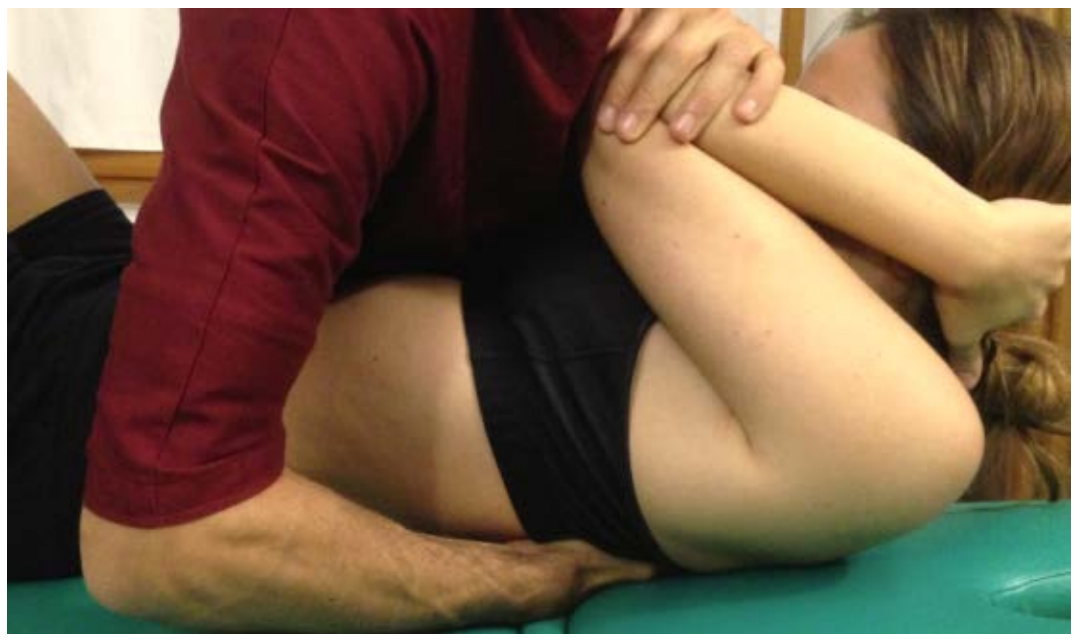

Figure 2. Dorsal spine (upper-mid thoracic segment). 


\subsection{HVLA, Dorsal Spine (Seated Thoracic Spine Distraction Thrust Manipulation)}

The therapist places the upper chest at the level of the patient's middle thoracic spine and grasps the patient's elbows. A high-velocity distraction thrust is performed in an upward direction [5] [7] (Figure 3).

\subsection{HVLA, Cervical Spine Thrust Joint Manipulation}

The therapist uses the manipulative (left) hand to localize the motion segment targeted and uses both hands to perform a high-velocity, low-amplitude thrust into rotation, which was directed up towards the patient's contra-lateral eye [5] [7] [8] (Figure 4).

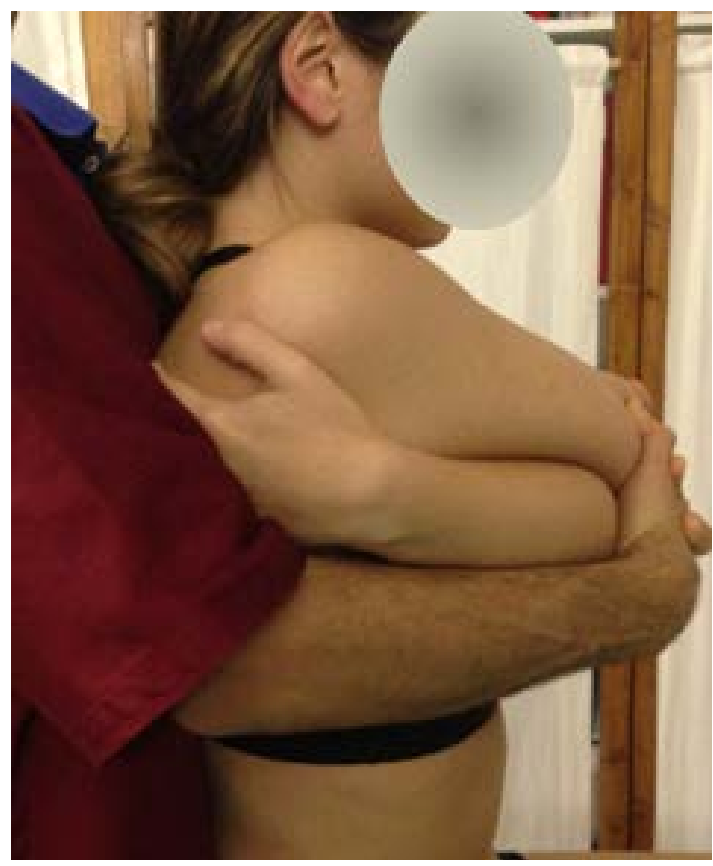

Figure 3. Dorsal spine (seated thoracic spine distraction thrust manipulation).

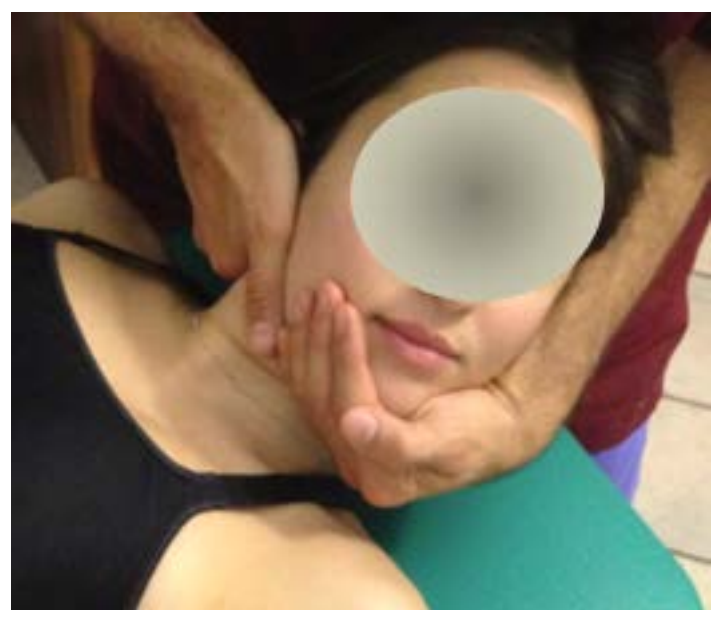

Figure 4. Cervical spine thrust joint manipulation. 


\subsection{Manual Therapy Techniques Addressing Trigger Points (TrPs) in the Forearm Muscles}

One hand of the therapist stabilizes the skin of the patient and the other hand performs a longitudinal stoker over the TrP taut band [9] [10] (Figure 5).

\subsection{Elbow Joint Mobilization/Manipulation}

The patients' forearm is supinated at the point of hypo-mobility. The pad of the thumb is placed posteriorly against the radial head. The technique consists of applying a posterior-anterior glide of the radial head [9] [10] (Figure 6).

\subsection{Mobilization with Movement Applied over the Elbow Region}

One hand of the therapist is used to glide the proximal forearm laterally, while the other hand fixed the distal end of the humerus while the patient performed a pain free gripping action. Ten repetitions are performed with an approximate 15-second rest interval between repetitions [7] [10] (Figure 7).

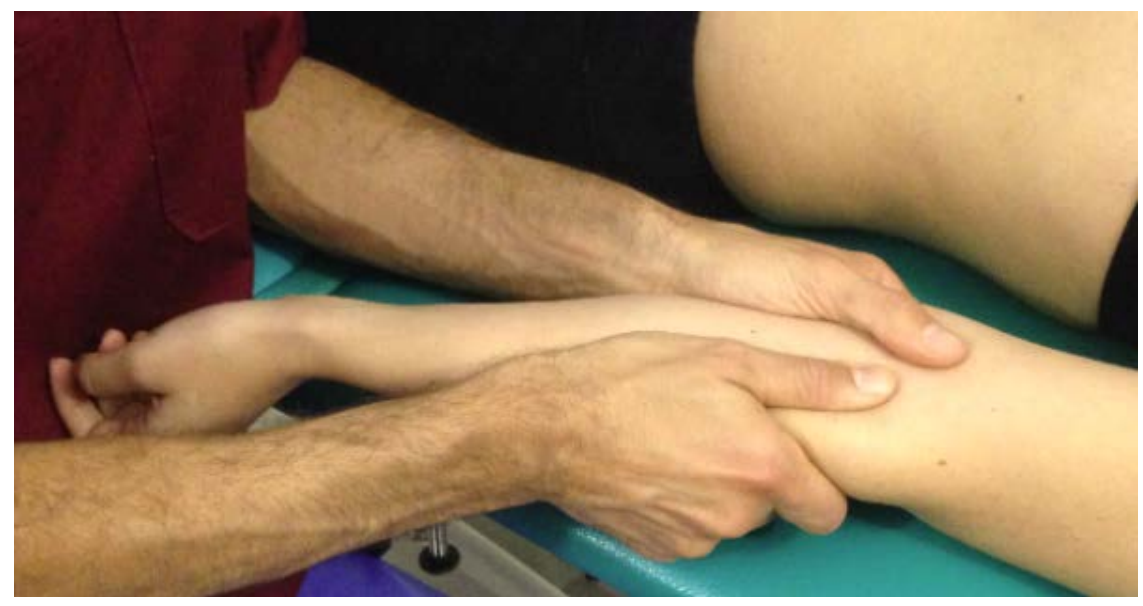

Figure 5. Manual therapy techniques addressing trigger points (TrPs) in the forearm muscles.

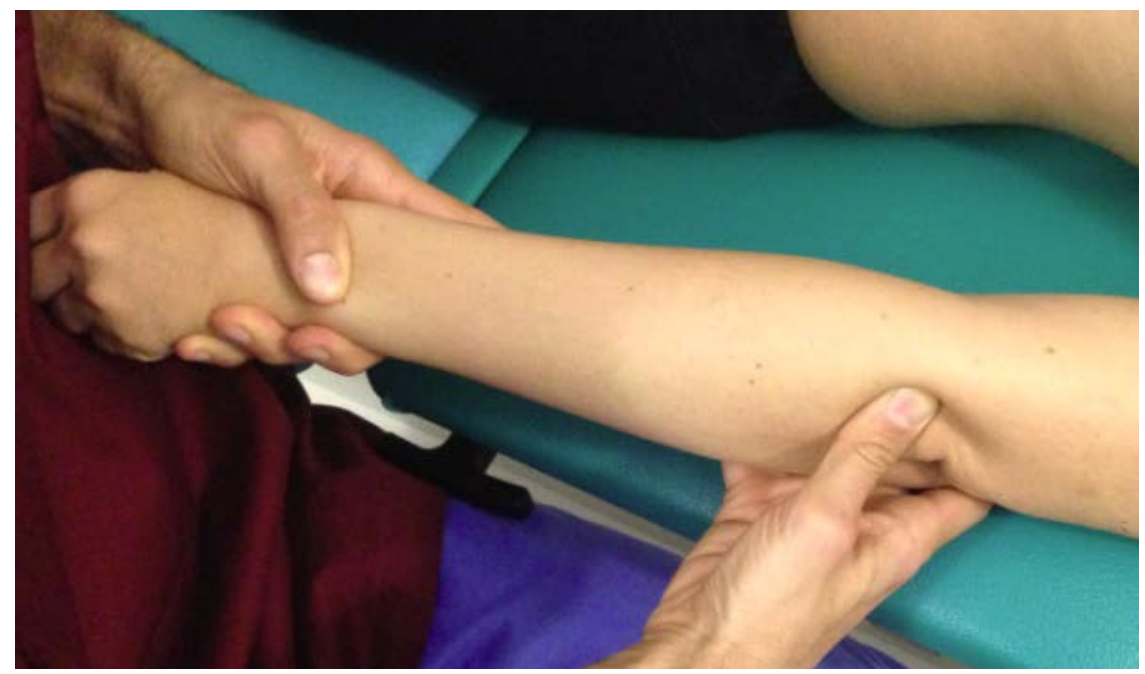

Figure 6. Elbow joint mobilization/manipulation. 


\subsection{ST, Manual Therapy Technique Targeting the Carpal Tunnel}

The therapist places his thumbs on the region of the carpal tunnel and flexes the index fingers over the back of the wrist forming a clamp. Holding the patient's wrist, the therapist applies a three-dimensional traction while slightly extending the wrist [9] [10] (Figure 8).

\subsection{Neurodynamic Technique Targeted to the Median Nerve}

(Left) shoulder girdle depression, gleno-humeral abduction and lateral rotation, supination of the forearm, elbow flexion and wrist, thumb, and finger extension; (right) shoulder girdle depression, gleno-humeral abduction and lateral rotation, supination of the forearm, elbow extension and wrist, thumb, and finger flexion [11] [12] (Figure 9).

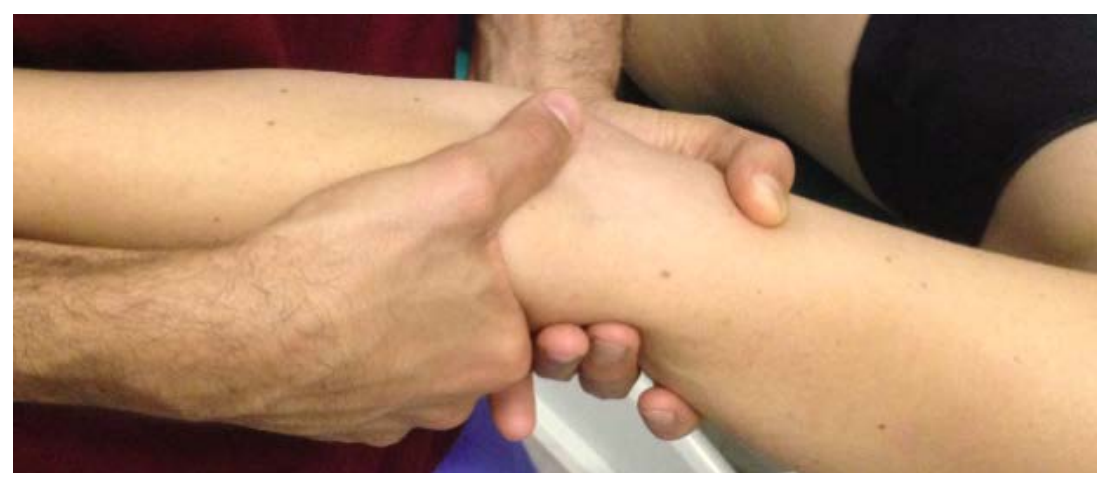

Figure 7. Mobilization with movement applied over the elbow region.

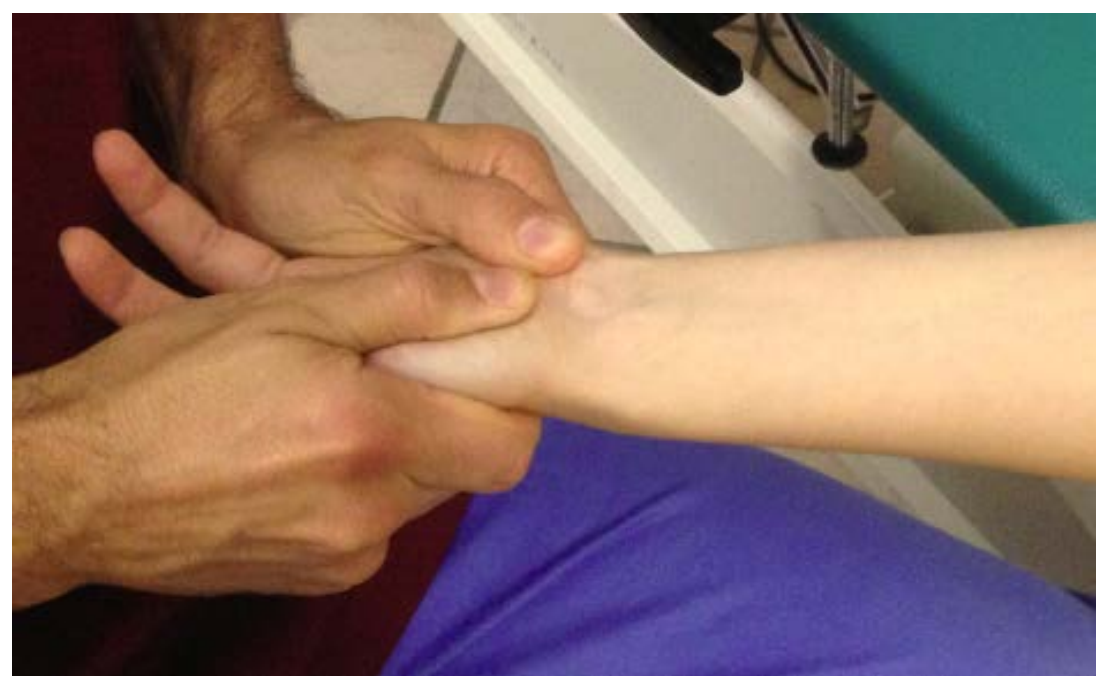

Figure 8. Manual therapy technique targeting the carpal tunnel.
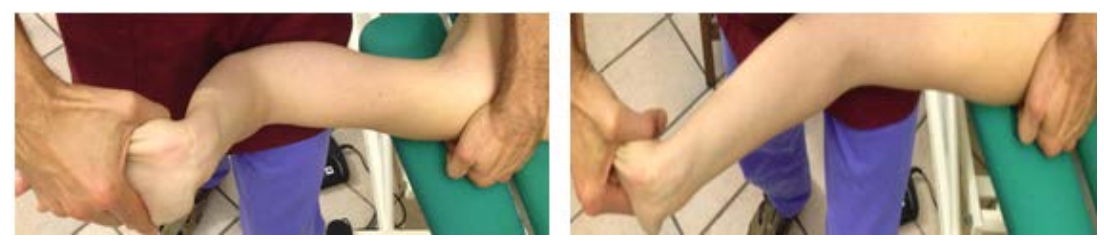

Figure 9. Neurodynamic technique targeted to the median nerve. 


\section{Lower Quadrant}

\subsection{HVLA, Sacroiliac Joint}

(Right HVLA-Sacroiliac Joint): with the patient in the lateral decubitus position, if one side is more painful than the other it is positioned at the top (e.g. painful left side). The osteopath is positioned in front of the patient and searches the area of transition between the iliac and the sacrum: The leg is flexed until it sets the vertebral segment dysfunction in motion, with a rest in the popliteal fossa of the opposite leg, which is extended. Subsequently, the therapist holds the patient from the lower part of the shoulder, and brings the left side of the trunk in flexion and left rotation, until the movement arrives at the dysfunctional vertebral segment. The patient's arms are positioned around the left arm of the osteopath. Following this, the patient is rolled towards the osteopath. Finally, the right arm of the osteopath applies a HVLA thrust to the pelvis in an anterior direction [5] [13] [14] (Figure 10).

\subsection{HVLA, Lumbar Neutral Manipulation}

(Patient Side lying, painful or treatment side up). Flex the top leg until you first begin to palpate motion at segmental interspace; place the patient's foot in the popliteal fossa as shown. Grasp the patient's bottom arm and shoulder and induce side bending and rotation until you begin to palpate motion at the segmental interspace. Have patient cross their arms by holding their own elbows. Reach through patient's arms. Gently grasp patient's side using broad hand contact and rotate the thorax backward.

Execution of the maneuver. While maintaining your setup log roll the patient towards you. Use your lower forearm and body to rotate the pelvis in opposite direction, Use your body to take up the slack and induce a HVLA thrust in anterior direction [5] [8] (Figure 11).

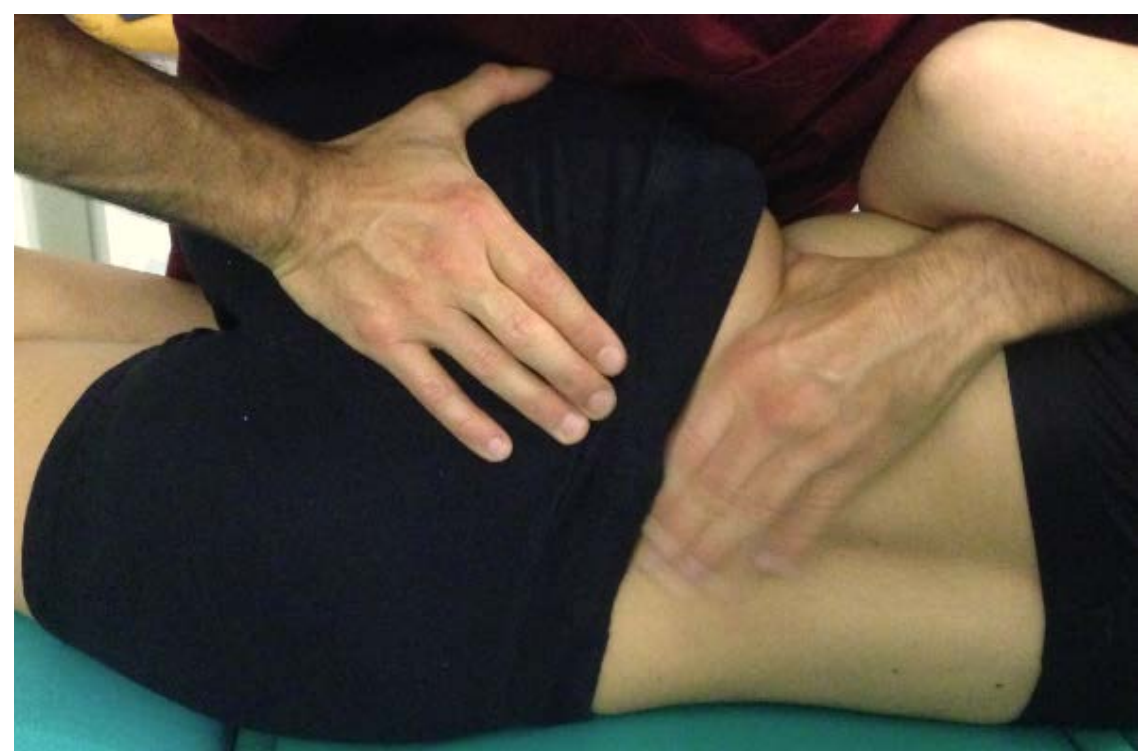

Figure 10. Sacroiliac joint. 


\subsection{Hip Caudal Glides in Supine with Belt (MWM)}

Patient supine towards the edge of the plinth, hip flexed to $90^{\circ}$, knee allowed to fully flex to comfort.

Execution of the maneuver. Flex the hip into resistance up to $90^{\circ}$, hold the thigh against your body. position mobilization belt pad in patient's hip crease; strap belt around your hips. Apply graded caudal mobilizations by using a rocking motion with your body. Adjust the amount of hip flexion, rotation, and adduction. Apply large-amplitude oscillations out of resistance (grade II) or into resistance (grade III), or small amplitude into resistance (grade IV). A sustained caudal glide while passively applying pain free flexion and/or internal rotation [5] [15] (Figure 12).

\subsection{Hip Posterior-Anterior Glides (MWM)}

Patient Prone, with hip resting in various degrees of flexion, abduction and external rotation.

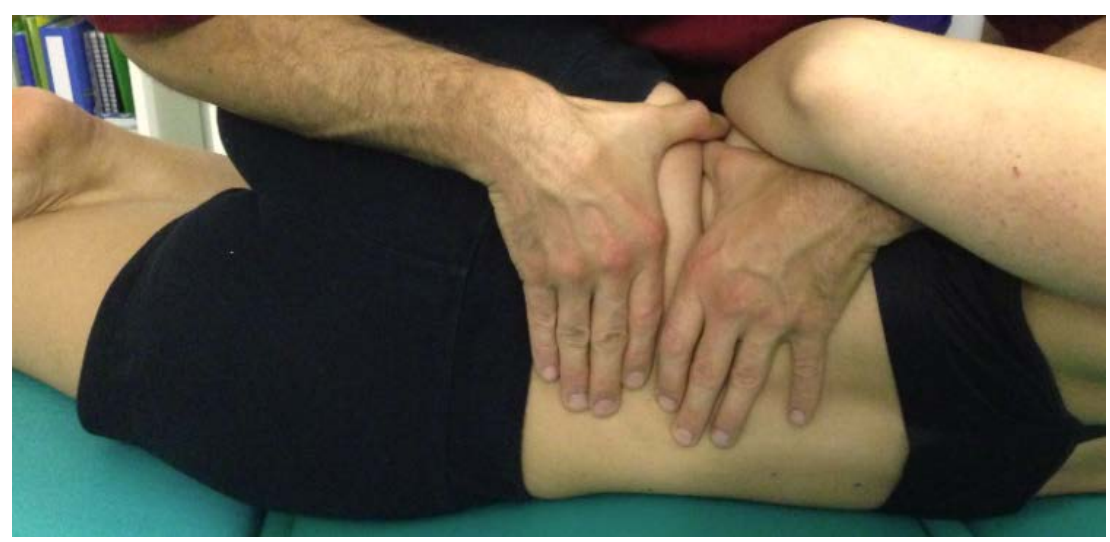

Figure 11. Lumbar neutral manipulation.

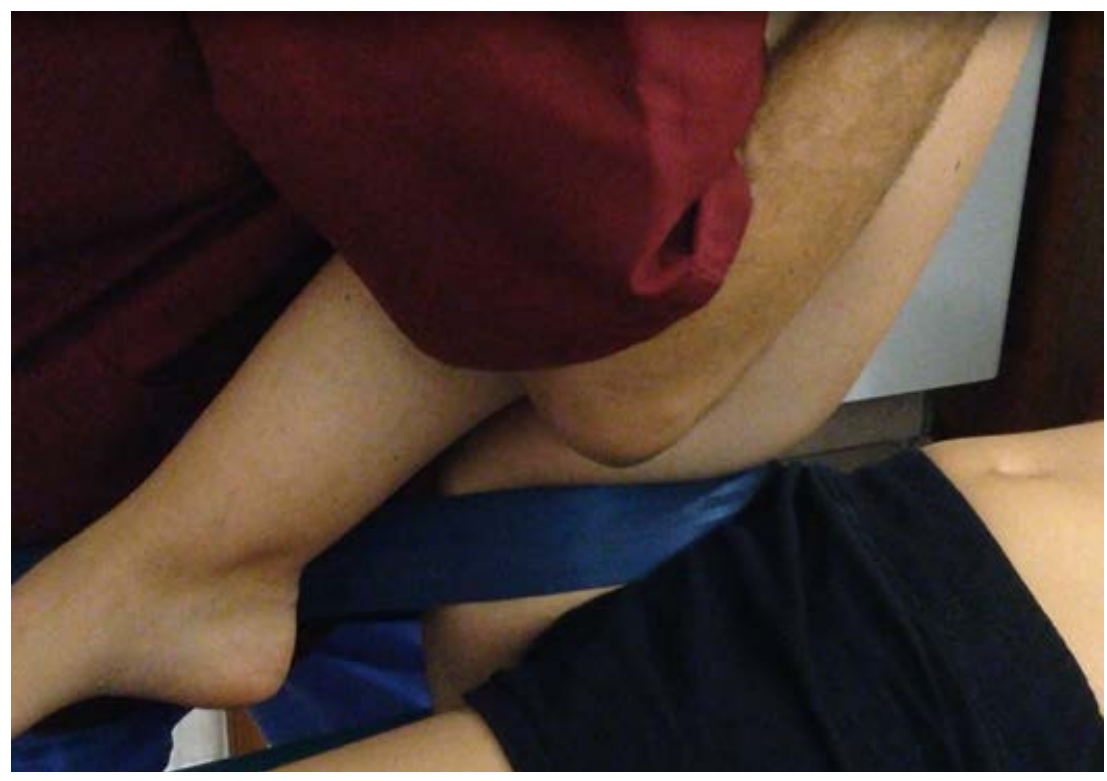

Figure 12. Hip caudal glides in supine with belt (MWM). 
Execution of the maneuver. Place both hands over posterior proximal femur, distal to hip joint. Position yourself directly over hip, elbows .localize the stretch the anterior capsule. Use your body to apply graded mobilizations to the hip joint. Direction of force is posterior to anterior with a slight medial inclination. Vary the direction of force based on stiffness and patient response. Apply largeamplitude oscillations out of resistance (grade II) or into resistance (grade III), or small amplitude into resistance (grade IV), [5] [15] [16] [17] (Figure 13).

\subsection{Hip Long Axis Distraction}

(Longitudinal Mobilization/Manipulation (HVLA) at the hip): Patient Supine, both legs resting on the plinth.

Execution of the maneuver. Stand on the ipsilateral side at the foot of the plinth, with both hands, grasp patient's distal tibia, just proximal to the malleoli, lift the leg into about $30^{\circ}$ hip flexion, slight abduction and slight external rotation, the knee fully in extension. Apply a long axis distraction force by completely extending your elbows and leaning back with your body weight. Using your body weight distract to resistance and watch for the pelvis to drop with each weight shift. You can add varying amounts of hip Internal rotation/external rotation, or adduction/abduction to achieve the desired effect of mobilization. When desired motion and tension achieved, you may either apply graded long axis mobilization, or a high velocity low amplitude thrust in a long axis direction [5] [15] [18] (Figure 14).

\subsection{HVLA, Fibular Head Manipulation}

Patient Supine with knee flexed.

Execution of the maneuver. Proximal hand: Grasp the posterior proximal tibia just medial to fibular head. Move soft tissue laterally until 2nd metacarpal phalangeal joint is against posterior fibular head. Distal hand: Serves as the movement hand by grasping the distal tibia. Rotate the tibia into external rotation with your movement. Engage barrier in knee flexion and apply Grade V mobilization (HVLA) into flexion direction [4] [5] [7] (Figure 15).

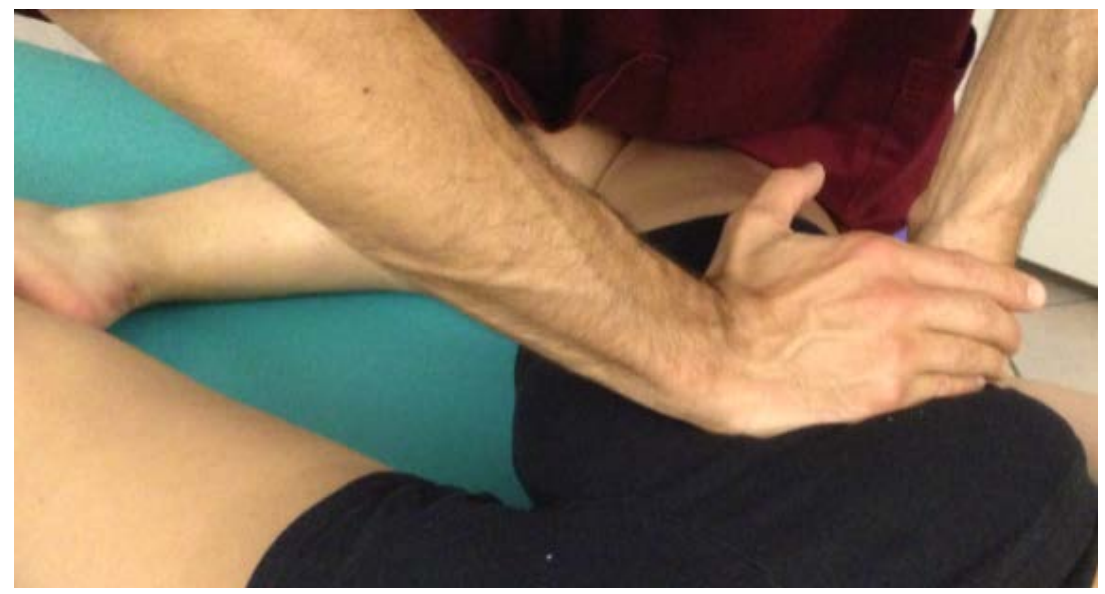

Figure 13. Hip posterior-anterior glides (MWM). 


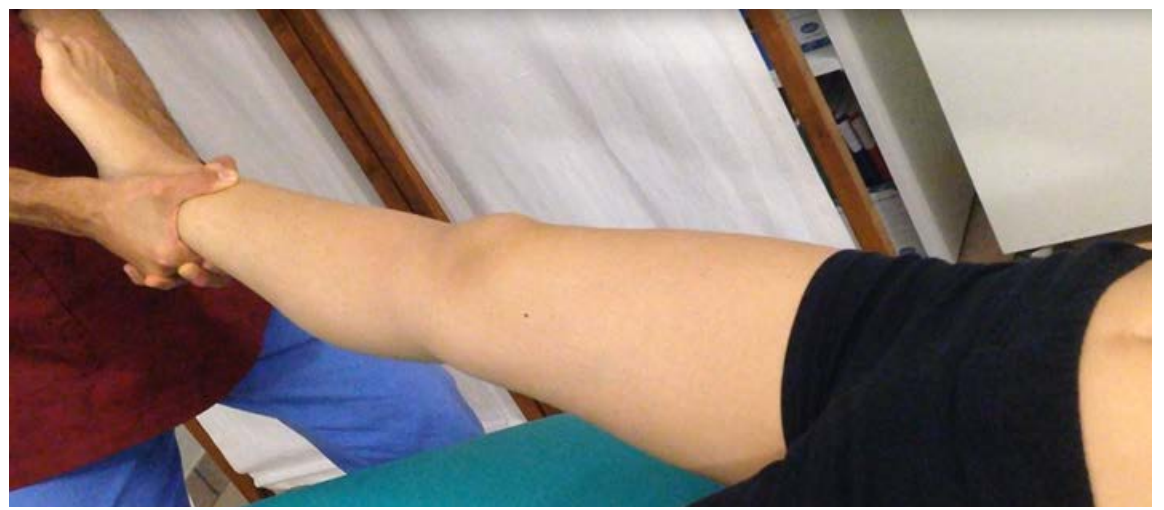

Figure 14. Hip long axis distraction.

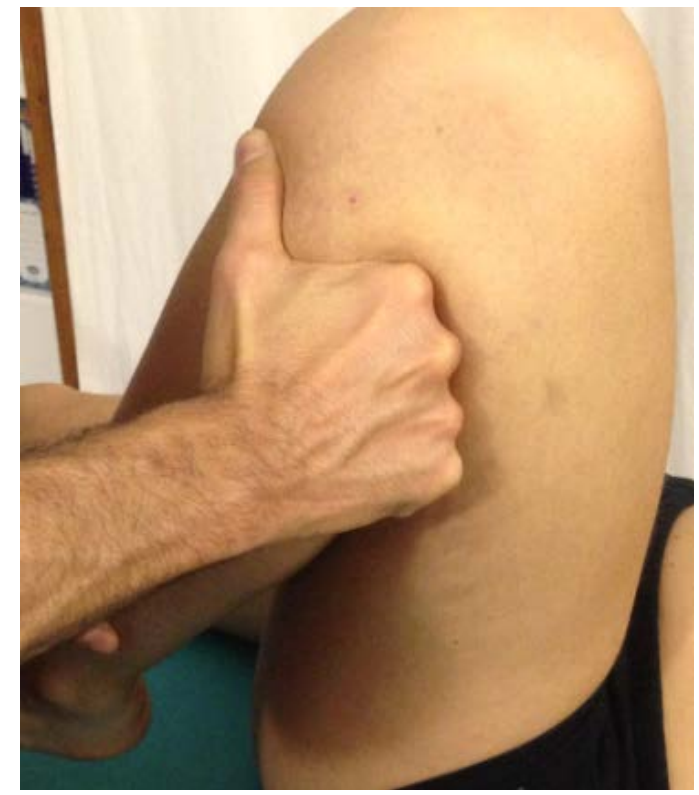

Figure 15. Fibular head manipulation.

\subsection{Tibio Fibular Mobilization Anterior-Posterior}

Supine, knee extended, foot slight off edge of table. Execution of the maneuver. Stabilizing hand grasps distal posterior tibia and rests it on the table. Mobilization hand uses either the thenar or hypothenar eminence on the anterior lateral malleolus,. Mobilize with an posteriorly directed force on the lateral malleolus [4] [5] [7] (Figure 16).

\subsection{HVLA, Rearfoot Distraction Manipulation}

Patient Supine, foot off the edge of the table.

Execution of the maneuver. Grasp the patient's foot with both hands. Small or ring fingers lie just below the neck of the talus. Both thumbs provide firm pressure to the mid forefoot. Engage restrictive barrier with ankle dorsiflexion eversion, slight pronation and distraction. Bring the ankle eversion and flexion forefoot to restrictive barrier. Apply a HVLA thrust in a caudal direction [4] [5] [7] (Figure 17). 


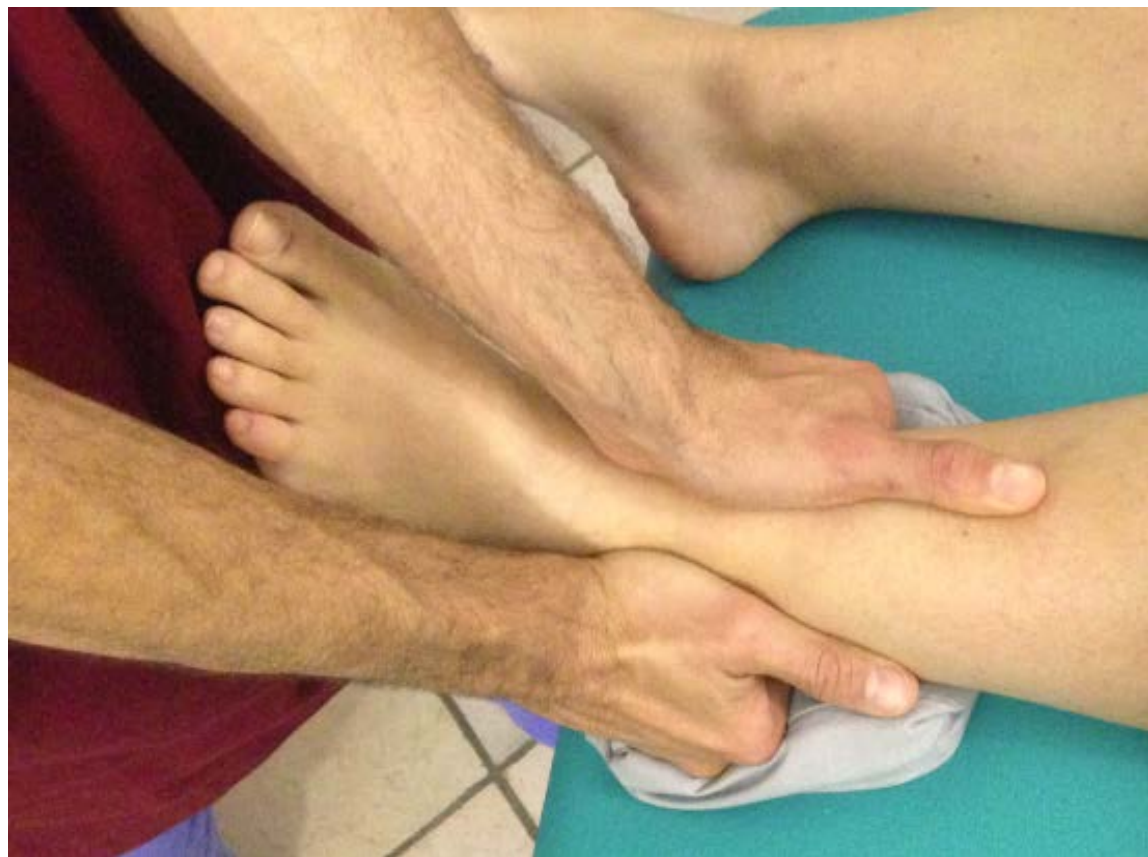

Figure 16. Tibio fibular mobilization anterior-posterior.

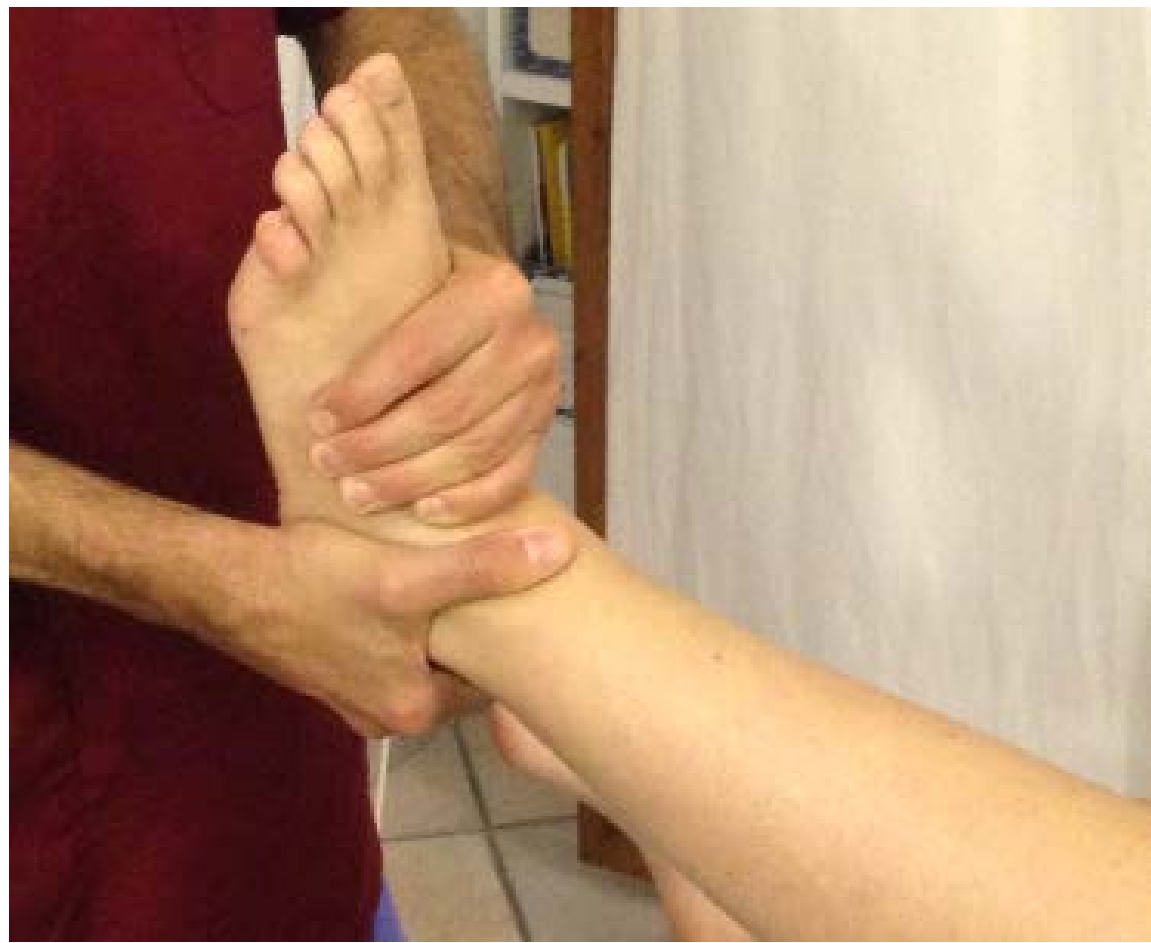

Figure 17. Rearfoot distraction manipulation.

\section{Front Quadrant}

\subsection{MET, Lower Thoracic Cage Release (Diaphragm)}

Execution of the maneuver. The osteopath's hands are placed at the level of the middle and lower thoracic structures, with the fingers along the costal arch. The structure is treated as though it were a cylinder, the hands testing the preference 
of this cylinder to rotate to the left and right along its central axis. Once the direction of greater rotational limitation has been established, the same assessment is made regarding the left and right lateral flexion. Once the two positions of restriction have been established, they are combined together and maintained. At this point the patient is asked to breathe in and hold their breath, and a Valsalva maneuver is performed for 3 - 4 seconds., then repeated for 3 - 4 breaths [6] [19] [20] (Figure 18).

\subsection{VIS, Mesenteric Lift}

Execution of the maneuver The thumbs or piriformis are positioned gently in the transverse direction on the projection of the mesenteric root, transversely to the centre of the line between the navel and the anterior superior iliac spine (ASIS). A thrust is applied to the visceral package, towards the pubic symphysis, so as to expect a counterthrust in return.

This is to be repeated a number of times, as if playing with the string of a bow, in order to redirect the tensions of the tissue. This can be aided by the respiratory cycle [6] [21] [22] (Figure 19).

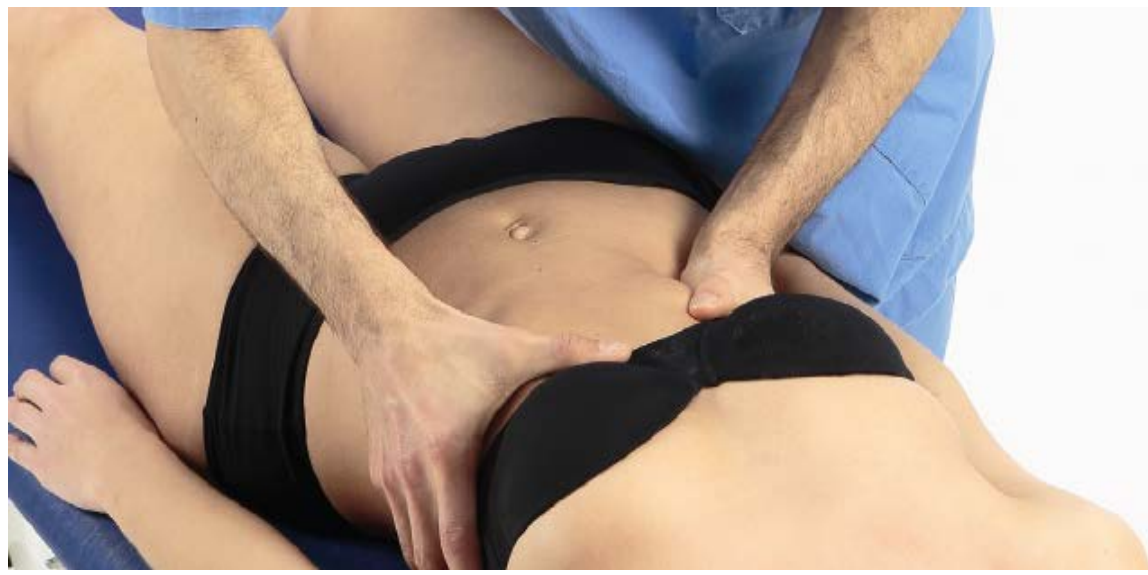

Figure 18. Lower thoracic cage release (diaphragm).

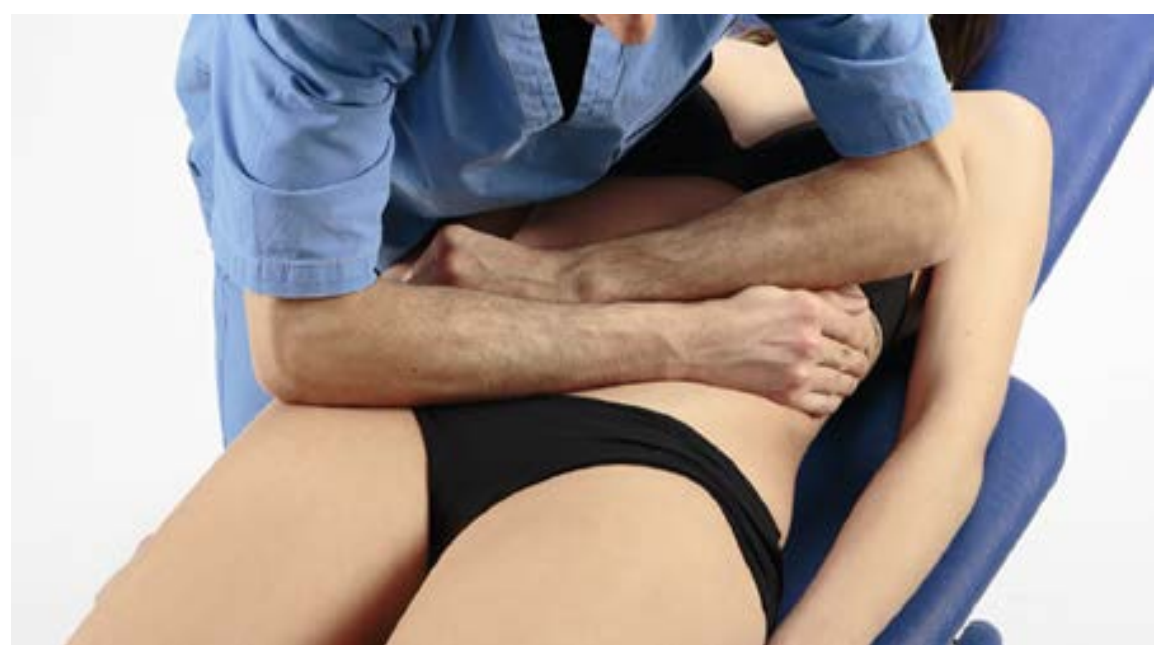

Figure 19. Mesenteric lift. 


\subsection{MET, Psoas Muscle (Supine Position)}

Execution of the maneuver. The patient is in a supine position with their legs off the bed, with the leg not being treated fully flexed at the hip and knee. The osteopath stands opposite the side to be treated, and the patient's foot on the same side as the flexed hip is brought against the side wall of the osteopath's abdomen. One of the osteopath's hands moves to the upper part of the knee and makes a slight downward thrust to extend the hip, while the other hand is at the level of the ASIS to incorporate the MB movement. Once the MB has been found the patient is asked to flex their hip in counter resistance for $7-10$ seconds. After the isometric contraction, when the patient exhales, the hip is extended (towards the floor), to attempt a new $\mathrm{MB}$, entirely painlessly, and the position is maintained for 30 seconds. The maneuver is repeated $3 / 4$ times in order to obtain an additional gain for each iteration [6] [7] [23] (Figure 20).

\subsection{HVLA, Lumbopelvic Manipulation}

Execution of the maneuver. Bring the pelvis toward the osteopath, performing a side-bending of the lower part of the patient with the limbs and trunk away from the osteopath. Thread the upper arm through the patient's arms, which are located behind the neck. Make contact with the contralateral front part of ASIS of the patient (side of the treatment) with the other hand. The other hand holds the top of the shoulder and the shoulder blade. This increases the rotation of the patient's trunk while maintaining the side in side banding. When performing this positioning, allow the ASIS to rise a few inches from the bed. The corrective action consists in performing a HVLA thrust with the hand resting on the ASIS, in a low behind direction [5] [6] [22] [24] (Figure 21).

\subsection{HVLA, Thoracic (Prone Position)}

Execution of the maneuver The osteopath is positioned with the hypothenar of

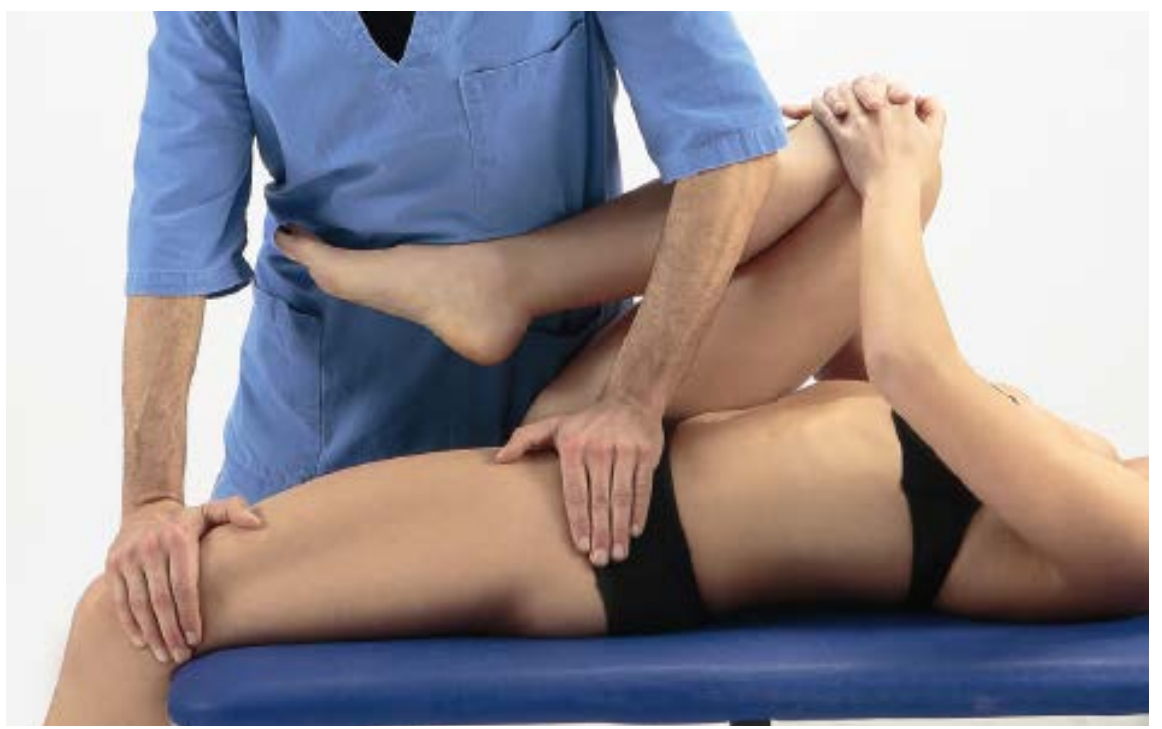

Figure 20. Psoas muscle (supine position). 
one hand on the transverse process of the dysfunctional vertebral segment, with the thenar eminence of the other hand on the opposing transverse process of the segment above or below that to be treated, placing a slight anterior pressure in order to find the motion barrier (MB) better and at the end of exhalation, without relieving the developed pressure, performing a high speed and small amplitude thrust in a forward direction in rotation with both hands (pressing in the classic butterfly motion with both hands) [6] [8] [14] (Figure 22).

\subsection{ST, Lumbar Spine}

Execution of the maneuver. The osteopath's thumbs are positioned on either side of the spinal column, in contact with the paravertebral muscles overlying the transverse processes, with the fingers fanned sideways starting from the L5 transverse processes. The two thumbs exert a gentle force in the ventral direction in order to engage the soft tissue, until reaching the barrier or limit to the movement of the tissue moving in the cranial direction up to the dorsolumbar junction. The maneuver is repeated in a gentle, slow rhythmic manner 3 - 4 times. [6] [25] (Figure 23).

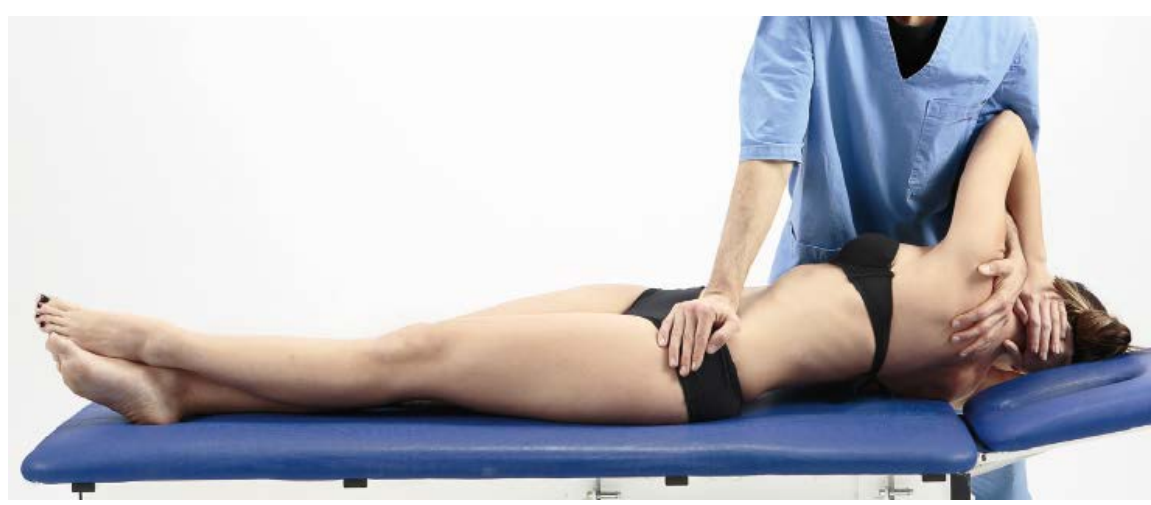

Figure 21. Lumbopelvic manipulation.

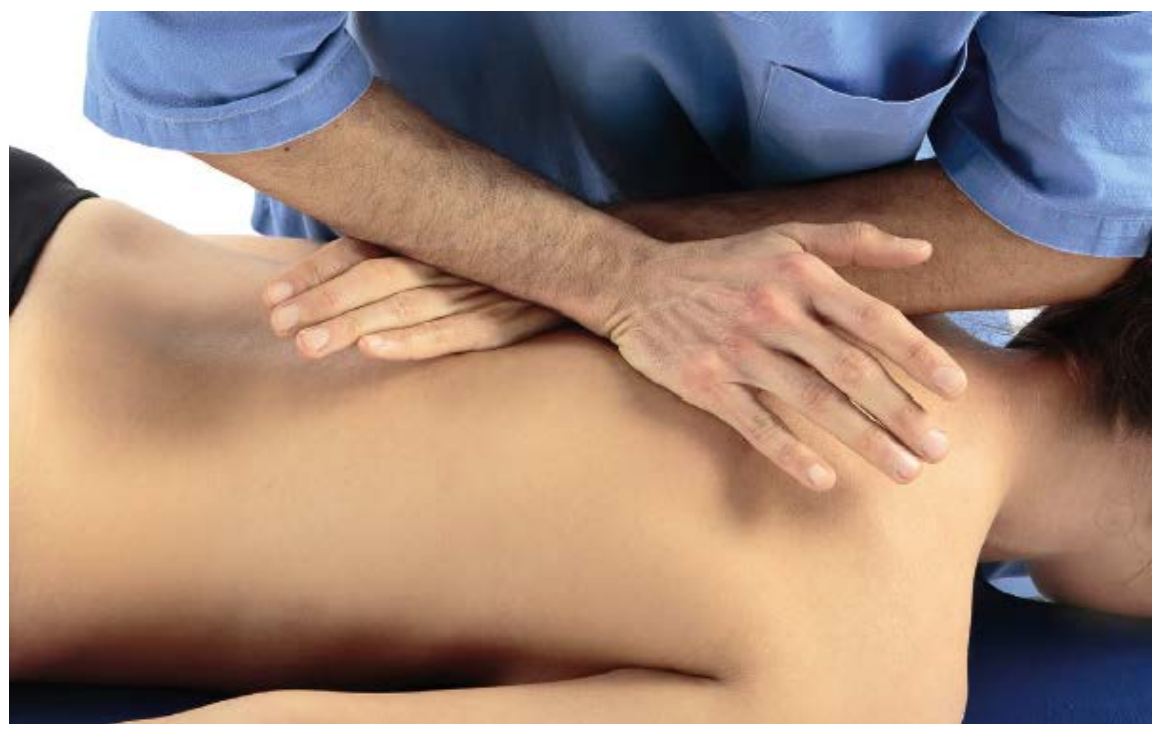

Figure 22. Thoracic (prone position). 


\subsection{S/C, T12L1}

Execution of the maneuver. One of the osteopath's hands is at the level of the dorsal-lumbar hinge, moving to find the tender side area at the level of the lateral mass of L1, or the medial tender area that lies medially with the spinous apophysis of L1. The other hand reaches for the ASIS, opposite the position of the osteopath, which is raised gently upwards to induce extension and rotation, to bring the tension towards the other hand that exerts pressure on the tender point. The pressure exerted in the tender area can be maintained for 30 seconds to 1 minute, in order to create an inhibitory function, or rhythmic pressure can be applied until changes are experienced in the tension of the tissue. The overall duration of the maneuver lasts for about two minutes [5] [6] [14] (Figure 24).

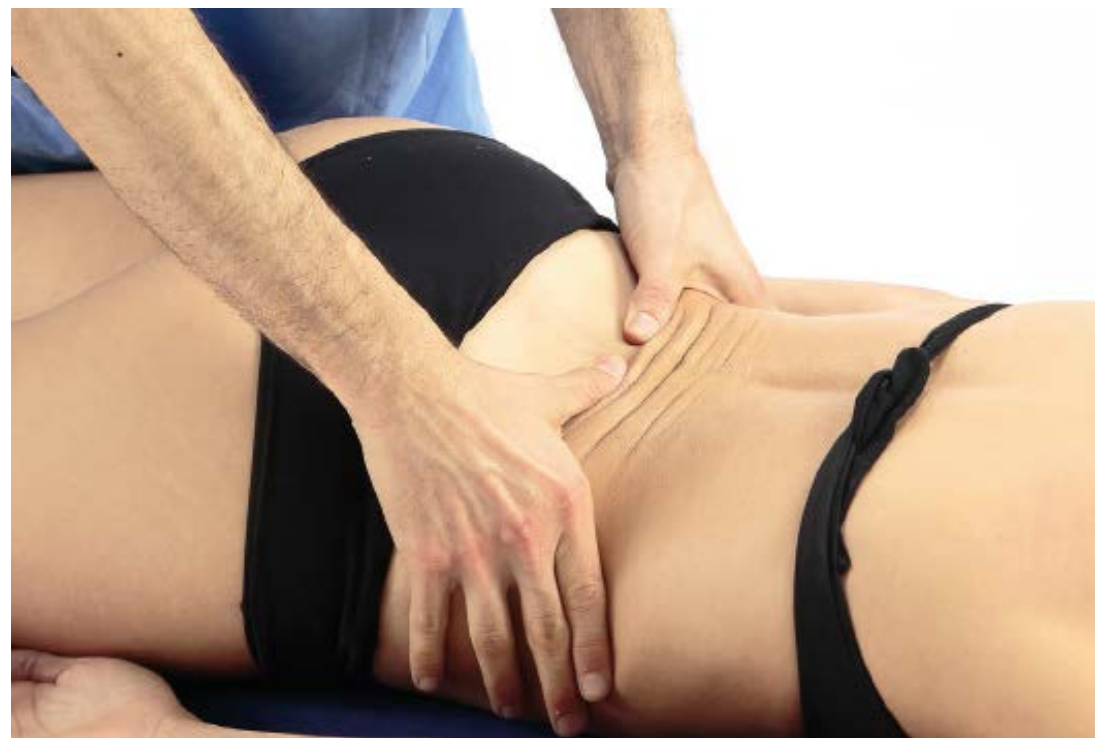

Figure 23. Lumbar spine.

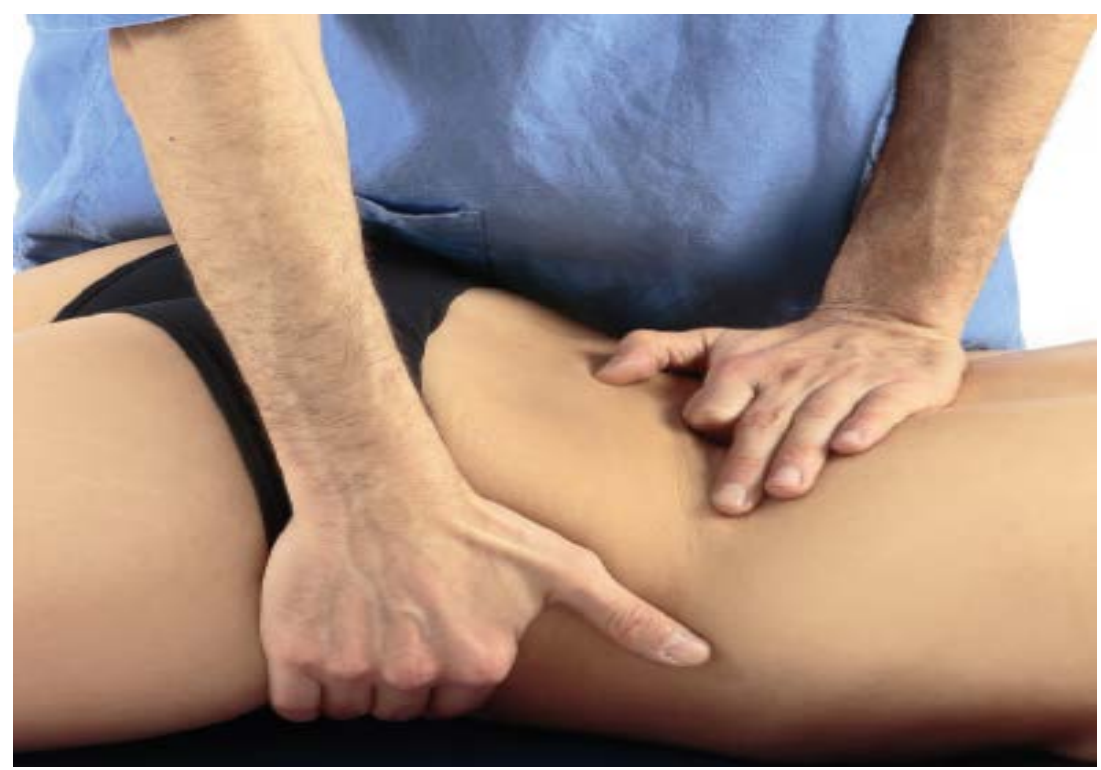

Figure 24. T12L1. 


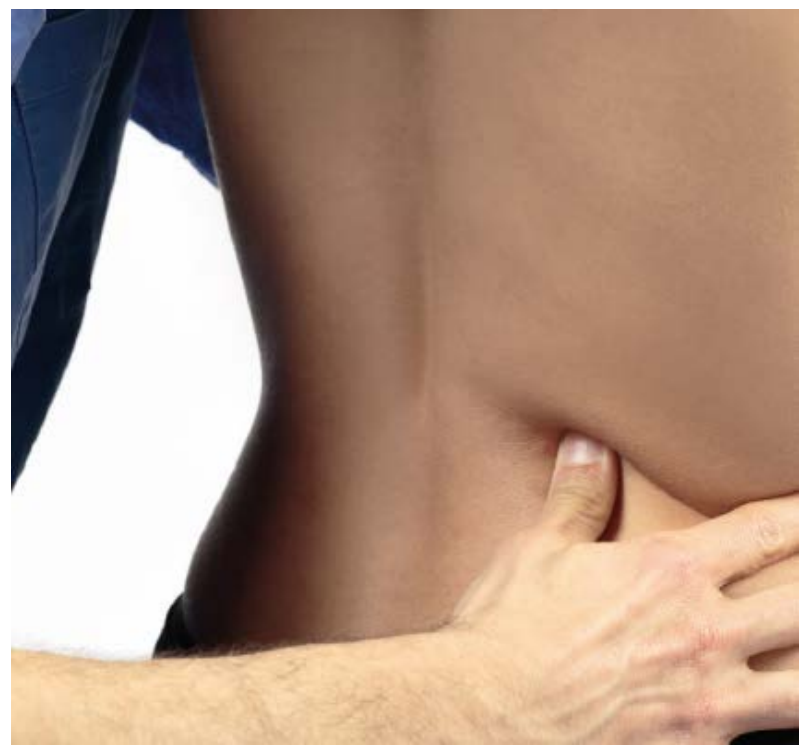

Figure 25. Large intestine.

\subsection{CRPs, Large Intestine}

Execution of the maneuver. With the patient sitting, once the NLR point has been found with the index, middle finger or the thumb, an approximation of tissues is made before taking the reflex point well under the finger, then maintaining constant pressure by performing a rotational movement (taking care that the finger does not slip) in the entire area of the NLR, for a period of $30-60$ seconds [6] [22] [26] (Figure 25).

\section{References}

[1] Tozzi, P. (2012) Selected Fascial Aspects of Osteopathic Practice. Journal of Bodywork and Movement Therapies, 16, 503-19. https://doi.org/10.1016/j.jbmt.2012.02.003

[2] Still, A.T. (1892) The Philosophy and Mechanical Principles of Osteopathy. Hudson-Kimberly Publication Co., Kansas City.

[3] Glossary of Osteopathic Terminology, Prepared by the Educational Council on Osteopathic Principles (ECOP) of the American Association of Colleges of Osteopathic Medicine (AACOM). Revised November, 2011.

[4] Greenman, P.E. (1996) Principles of Manual Medicine. Williams \& Wilkins, Baltimore.

[5] Robert Boyles, P.T., Timothy, W., Flynn, P.T., Julie, M., Whitman, P.T., Robert, S., Wainner, P.T., Paul, E. and Mintken, P.T. (2012) Spinal \& Extremity Manipulation. The Basic Skill Set. 2nd Edition, EIM (Evidence in Motion), Louisville.

[6] Lombardini, R. and Collebrusco, L. (2016) Osteopathy and Nutrition for Managing the Irritable Bowel Syndrome-Brief and Useful Guide. 1st Edition, Editor. Universitas Studiorum S.r.l., Mantova.

[7] Di Giovanna, E.L., Schiowitoz, S. and Dowling, D.J. (2005) An Osteopathic Approach to Diagnosis and Treatment. 3rd Edition, Lippincott Williams \& Wilkins, Philadelphia.

[8] McCarthy, C. (2010) Combined Movement Theory Rational Mobilization and Ma- 
nipulation of the Vertebral Column. Churchill Livingstone, London.

[9] Fernandez-Carnero, J., Fernandez-de-las-Penas, C., de la Llave-Rincon, A.I., Ge, H.Y. and Arendt-Nielsen, L. (2007) Prevalence of and Referred Pain from Myofascial Trigger Points in the Forearm Muscles in Patients with Lateral Epicondylalgia. Clinical Journal of Pain, 23, 353-360. https://doi.org/10.1097/AJP.0b013e31803b3785

[10] Slater, H. and Fernandez de las Penas, C. (2011) Joint Mobilization and Manipulation of the Elbow. In: Fernandez-de las Penas, C., Cleland, J.A. and Huijbregts, P., Eds., Neck and Arm Pain Syndromes: Evidence-Informed Screening, Diagnosis and Conservative Management, Churchill-Livingstone, London, 328-334. https://doi.org/10.1016/B978-0-7020-3528-9.00025-X

[11] Butler, D.S. and Coppieters, M.W. (2007) Neurodynamics in a Broader Perspective. Manual Therapy, 12, e7-e8. https://doi.org/10.1016/j.math.2007.01.001

[12] Coppieters, M.W. and Butler, D.S. (2008) Do "Sliders" Slide and “Tensioners" Tension? An Analysis of Neurodynamic Techniques and Considerations Regarding Their Application. Manual Therapy, 13, 213-221.

https://doi.org/10.1016/j.math.2006.12.008

[13] Cleland, J.A., Fritz, J.M., Childs, J. and Kulig, K. (2006) Comparison of the Effectiveness of Three Manual Physical Therapy Techniques in a Subgroup of Patients with Low Back Pain Who Satisfy a Clinical Prediction Rule: Study Protocol of a Randomized Clinical Trial [NCT00257998]. BMC Musculoskeletal Disorders, 7, 11. https://doi.org/10.1186/1471-2474-7-11

[14] Collebrusco, L. (2014) Positional Release Techniques as a Diagnostic-Therapeutic Approach in Physiotherapy. Open Journal of Therapy and Rehabilitation, 2, 19-20. https://doi.org/10.4236/ojtr.2014.21004

[15] Beselga, C., Neto, F., Alburquerque-Sendín, F., Hall, T. and Oliveira-Campelo, N. (2016) Immediate Effects of Hip Mobilization with Movement in Patients with Hip Osteoarthritis: A Randomised Controlled Trial. Manual Therapy, 22, 80-85. https://doi.org/10.1016/j.math.2015.10.007

[16] Hing, W. (2008) Mulligan's Mobilisation with Movement: A Review of the Tenets and Prescription of MWMs. New Zealand Journal of Physiotherapy, 36, 144-161.

[17] Barak, T., Rosen, E. and Sofa, R. (1985) Mobility: Passive Orthopedic Manual Therapy. In: Gould, J. and Davies, G., Eds., Orthopedic and Sports Physical Therapy, CV Mosby, St. Louis, 212-227.

[18] Hoeksma, H., Dekker, J., Ronday, H., Heering, A., Van Der Lubbe, N. and Cees, V. (2004) Comparison of Manual Therapy and Exercise Therapy in Osteoarthritis of the Hip: a Randomized Clinical Trial. Arthritis and Rheumatism, 51, 722-729. https://doi.org/10.1002/art.20685

[19] Degenhardt, B.F. and Kuchera, M.L. (1996) Update on Osteopathic Medical Concepts and the Lymphatic System. Journal of the American Osteopathic Association, 96, 97-100.

[20] Chaitow, L., Bradley, D. and Gilbert, C. (2002) Multidisciplinary Approaches to Breathing Pattern Disorders. Churchill Livingstone, London, 51, 86.

[21] Kuchera, M.L. and Kuchera, W.A. (1994) Osteopathic Consideration in Systemic Dysfunction. 2nd Edition, Greyden Press, Columbus.

[22] Collebrusco, L. and Lombardini, R. (2013) Osteopathic Manipulative Treatment and Nutrition: An Alternative Approach to the Irritable Bowel Syndrome. Health, 5, 87-93. https://doi.org/10.4236/health.2013.56A2013

[23] Chaitow, L. (2006) Muscle Energy Techniques. Elsevier, Amsterdam. 
[24] Steel, K.M., et al. (2006) The Pocket Manual of OTM: Osteopathic Manipulative Treatment for Physicians. Lippincott Williams and Wilkins, Philadelphia.

[25] Chaitow, L. (1988) Soft-Tissue Manipulation: A Practitioner's Guide to the Diagnosis and Treatment of Soft Tissue Dysfunction and Reflex Activity. Healing Arts Press, Rochester.

[26] Modi, R.G. and Shah, N.A. (2006) Clinical Anatomy and Osteopathic Manipulative Medicine. Lippincott Williams and Wilkins, Philadelphia. 


\section{Appendix}

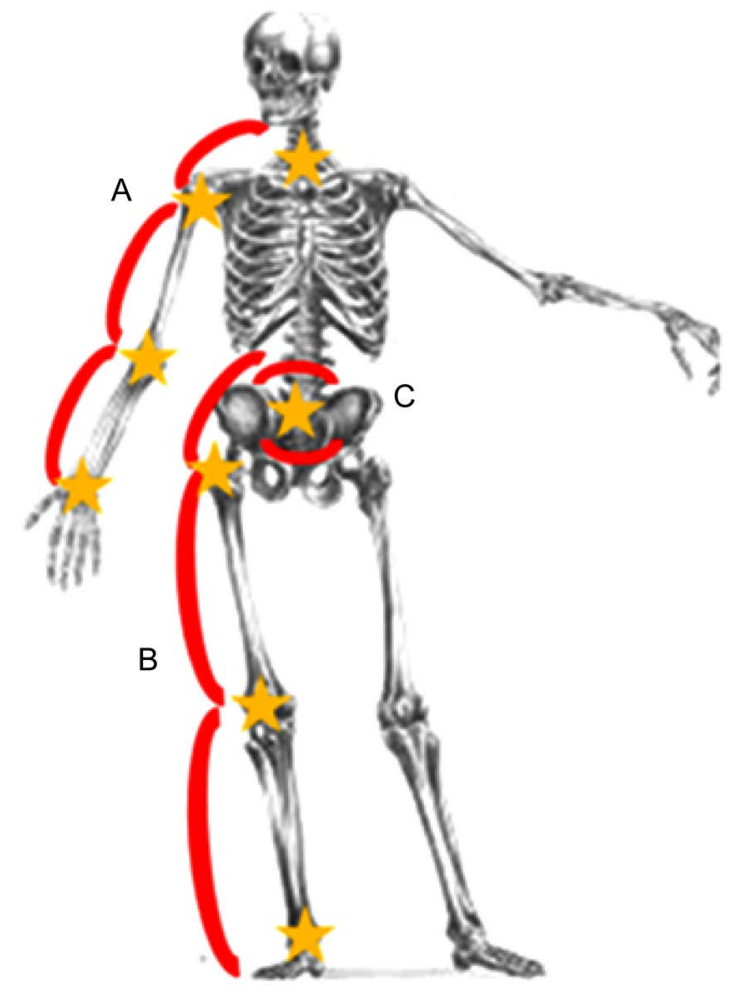

Figure A1. Lower Quadrant (A); Front Quadrant (B); Upper Quadrant (C). From: Collebrusco L., Lombardini R., Censi G. "Regional Interdependence: A Model That Needs to Be Integrated in the Functional Evaluation and Physiotherapy Treatment-Part 1", Open Journal of Therapy and Rehabilitation, 2016, 4, 117-124. http://dx.DOI.org/10.4236/ojtr.2016.43010

\section{Acronyms}

ASIS: Anterior Superior Iliac Spin

CRPs: Chapman's Reflex Points

Grade II: large amplitude movement at within the available ROM

Grade III: large amplitude movement that reaches the end ROM

Grade IV: small amplitude movement at the very end range of motion

Grade V: high velocity thrust of small amplitude at the end of the available range and within its anatomical range (manipulation)

HVLA: High-Velocity Low-Amplitude

MB: Motion Barrier

MET: Muscle Energy Technique

MWM: Mobilization With Movement

NLR: Neurolymphatic Reflexes

S/C: Strain/Counterstrain

ST: Soft Tissue

TrPs: Trigger Points

VIS: Visceral Manipulation 
Submit or recommend next manuscript to SCIRP and we will provide best service for you:

Accepting pre-submission inquiries through Email, Facebook, LinkedIn, Twitter, etc. A wide selection of journals (inclusive of 9 subjects, more than 200 journals)

Providing 24-hour high-quality service

User-friendly online submission system

Fair and swift peer-review system

Efficient typesetting and proofreading procedure

Display of the result of downloads and visits, as well as the number of cited articles Maximum dissemination of your research work

Submit your manuscript at: http://papersubmission.scirp.org/

Or contact ojtr@scirp.org 